УДК 621.3

Коновалов Юрий Васильевич,

к.т.н., доиент, заведуюший кафедрой «Электроснабжение промышленных предприятий», ФГБОУ ВО «Ангарский государственный технический университет», e-mail: yrvaskon@mail.ru

ОСНОВНЫЕ ЗАДАЧИ УПРАВЛЕНИЯ КАЧЕСТВОМ ЭЛЕКТРОСНАБЖЕНИЯ

Konovalov Y.V.

\title{
BASIC TASKS OF POWER QUALITY MANAGEMENT
}

Аннотация. Для решения многопараметрических и взаимосвязанных оптимизационных задач по обеспечению качества электроснабжения электротехнического комплекса промышленного предприятия предложена структура комплексной системы управления качеством электроснабжения, позволяющая измерять, собирать, хранить, обрабатывать и надлежащим образом представлять требуемую для управления информацию.

Ключевые слова: качество, электроснабжение, система, управление.

Abstract. To solve multi-parameter and interconnected optimization tasks to ensure the quality of power supply to the electrical complex of an industrial enterprise, the structure of an integrated power supply quality management system is proposed that allows you to measure, collect, store, process and properly present the information required for management.

Keywords: quality, power supply, system, management.

Качество электроснабжения - интегральный показатель, определяемый как взвешенная совокупность показателей, характеризующих надежность электроснабжения, качества электроэнергии, экономичность и электробезопасность [1]. Показатели качества электроснабжения разделяются на прямо влияющие на технологический процесс и косвенно влияющие на технологический процесс. К прямо влияющим на технологический процесс относятся следующие показатели: частота отказов, время ликвидации отказа, частота преднамеренных отключений, время преднамеренных отключений, к косвенно влияющим на технологический процесс - качество электрической энергии, снижение срока службы электрооборудования из-за искажения кривых тока и напряжения.

Качество управления электроснабжением определяется достижением требуемых значений, указанных выше прямых и косвенных показателей. Повышение показателей качества электроснабжения возможно организацией комплексной системы управления качеством электроснабжения (КСУЭ). Наиболее значимые задачи, стоящие перед КСУЭ приведены на рисунке 1, на котором указаны только наиболее важные классификационные отношения. Решение перечисленных задач управления системой электро- снабжения (СЭС) не допускает однозначной структуризации и требует полного согласования их между собой во времени и по универсальным показателям, характеризующим эффективность функционирования электроснабжения промышленного предприятия.

Проблема эффективного управления качеством электроснабжения требует взаимоувязанного решения целого спектра многопараметрических и взаимосвязанных задач оптимизационного характера. Эффективное решение взаимосвязанных задач, отраженных на рисунке 1, возможно при наличии достаточного объема исходных данных, касающихся состояния СЭС и среды взаимодействия. Последнее требование предполагает наличие мощной системы комплексного мониторинга состояния СЭС, позволяющей измерять, собирать, хранить, обрабатывать и надлежащим образом представлять требуемую для управления информацию $[1,2]$.

Сформированные решения должны приобретать форму соответствующих управляющих воздействий, для реализации которых требуется исполнительная управляющая система, система контроля исполнения и система документооборота.

Управляющая структура КСУЭ, отражающая общие связи при управлении качеством электроснабжения, представлена на рисунке 2. 


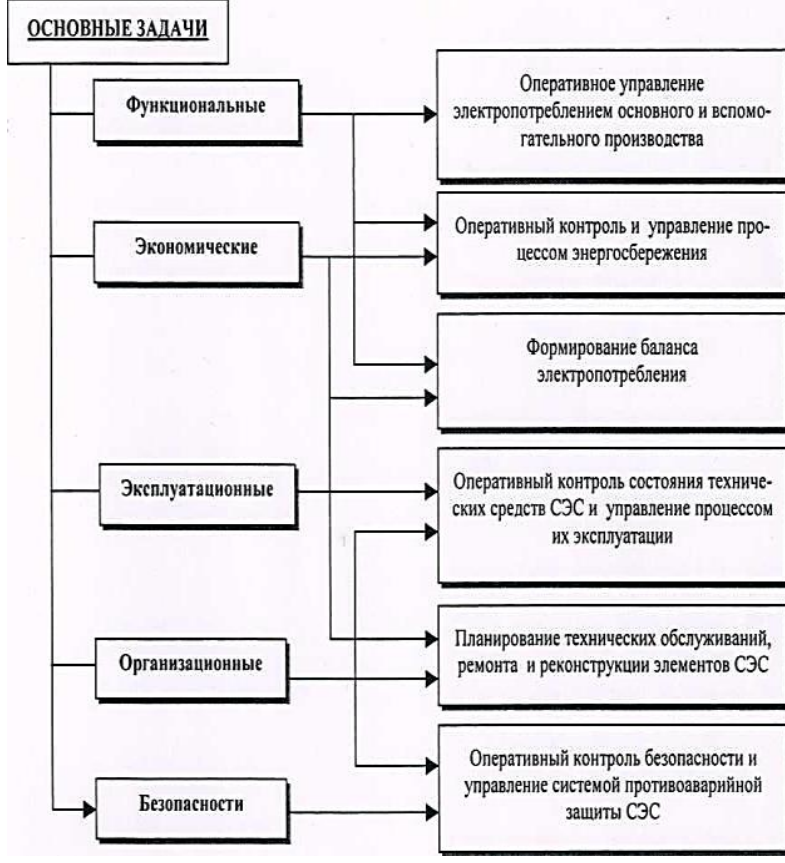

Рисунок 1 - Основные задачи, стоящие перед системой управления СЭС

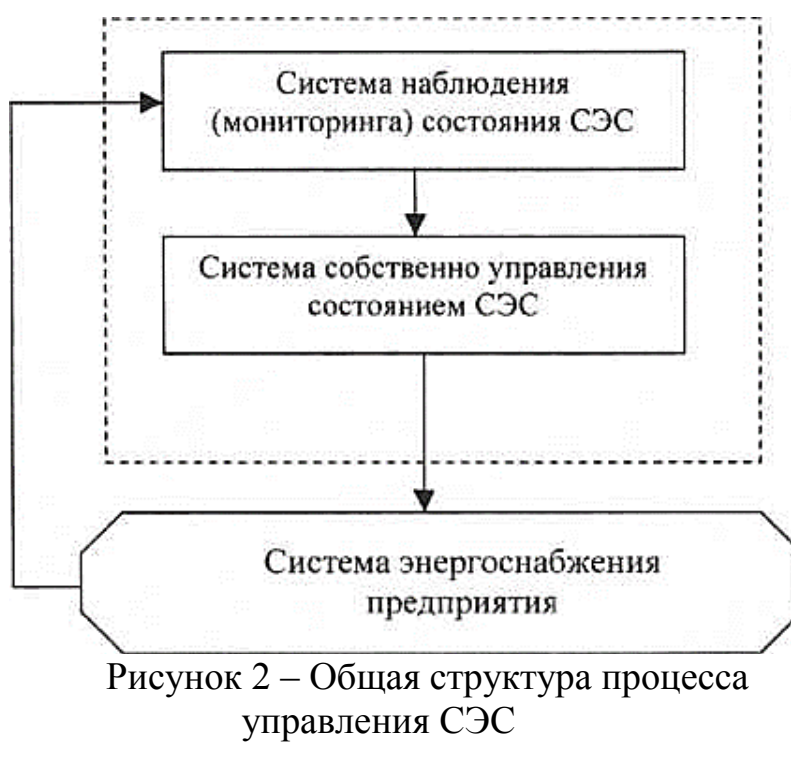

Состояние элементов системы электроснабжения можно описать вектором наблюдаемых параметров $x_{\langle 1: m\rangle}$. Эволюция $x(t)$ в общем случае описывается нелинейным дифференциальным уравнением вида:

$$
\dot{x}(t)=\varphi\{x(t), w(t)\},
$$

где составляющие вектора $w(t)$ определяются неизвестными или неточно известными факторами, воздействующими на СЭС и приводящими к ошибкам управления $[1,3]$.

Наличие опорных значений $x_{0}(t)$, отвечающих номинальным или среднестати- стическим значениям для известных состояний СЭС, позволяет перейти к линеаризованной модели эволюции вида:

$$
\dot{x}(t)=F(t) \cdot x(t)+G(t) \cdot w(t),
$$

где $F, G$ - известные матрицы размера $\langle\mathrm{m}: \mathrm{n}\rangle, \quad x(t)$ - вектор состояния энергосистемы предприятия для линеаризованной модели наблюдения, определяемый разностью между его истинным и прогнозируемым значением, $w(t)$ - случайная составляющая (собственные шумы системы) вектора состояния СЭС, определяемая в виде стохастического векторного процесса. Типичными (хотя и не всегда верными) предположениями относительно вероятностной природы $w(t)$ является утверждение об их гауссовости, стационарности и независимости, то есть:

$$
w_{k} \in N\left[0 ; Q_{k} \cdot \delta_{k i}\right]
$$

Главным источником информации относительно состояния СЭС предприятия являются их наблюдения (контрольнодиагностические и другие измерения). В качестве простейшей модели наблюдений (как правило, дискретной) используется линеаризованное отображение:

$$
z_{k}=H_{k} \cdot x_{k}+v_{k},
$$

где $v_{k}$ - погрешность измерений.

Таким образом, основными исходными данными для формирования аналитического управления являются оперативные измерения и динамические массивы ретроспективных наблюдений за состояниями СЭС и производственной средой $M$. Для их обработки необходимо использовать качественно новые подходы с использованием современных математических и информационных технологий.

В процессе управления качеством электроснабжения возникает задача комплексного освещения динамической ситуации $S(t-T, t)$, отражающей взаимодействие системы электроснабжения и производственной среды на заданном интервале времени $(t-T, t)$, где $t$ - текущее время. При этом, в зависимости от временного интервала относительно текущего момента времени $t$, имеют место задачи ситуационного, прогностического или ретроспективного анализа.

На основе проведенного анализа ситуаций, изложенного в [1], предложена структура комплексной системы управления 
качеством электроснабжения промышленного предприятия, включающая следующие подсистемы:

- режимы электропотребления;

- качество электроэнергии;

- надежность;

- мониторинг и организация эксплуатации.

Задачей подсистемы «Режимы электропотребления» является управление режимами активной и реактивной мощности в соответствии с ограничениями, вносимыми питающей энергосистемой в условиях применения дифференцированных тарифов на электрическую энергию и минимизация оплаты за электрическую энергию путем формирования рациональных графиков нагрузки.

Задачей подсистемы «Качество электроэнергии» является управление режимом напряжения на объектах электроснабжения на рациональном (близком к оптимальному) уровне и минимизация гармонических искажении (высших гармонических), вызванных нелинейными нагрузками.

Задачей подсистемы «Надежность» является снижение ущербов от перерывов электроснабжения и обеспечения долговечности электрооборудования в соответствии с его техническими характеристиками

Задачей подсистемы «Мониторинг и организация эксплуатации» является своевременное проведение диагностики и организация технических обслуживание ремонтов и реконструкции электрооборудования в соответствии с его фактическим техническим состоянием.

Таким образом, КСУЭ является сложной иерархической системой, задачей которой при формировании управленческого решения $d$ (или при выборе решения $d$ из множества допустимых решений $\{D\})$ является достижение наибольшего функционального и экономического положительного эффекта.

Подсистемы КСУЭ позволяют осуществить ситуационный анализ в сочетании с автоматизированным исследованием ретроспективных данных, отражающих опыт управления системами электроснабжения. Решение класса задач, характерных для комплексной системы управления качеством электроснабжения, и связанных с выявлением скрытых тенденций развития и факторов влияния, идентификацией неявных взаимозависимостей и взаимосвязей и т.п., позволяет повысить уровень информированности до величины $I 2$ (I2> I1). В результате этого может быть сформирован иной вариант допустимого решения $d_{2}\left(I_{2}\right) \in\{D\}$, обладающий более высокой эффективностью $Q(d 2)>Q$ (d1).

Разница показателей эффективности:

$$
\delta Q=Q(d 2)-Q(d 1)
$$

определяет положительный эффект, достигаемый за счет разработки и внедрения КСУЭ на предприятии.

Соотношение (5) носит функциональный характер. Например, в качестве показателя эффективности могут выступать величина бесперебойности электроснабжения основного и вспомогательного производства предприятия, величина экономии электроэнергии (энергосбережения) за отчетный период, вероятность безотказной работы системы электроснабжения и т.п. Однако этот же показатель допускает и экономическую интерпретацию, как отношение достигнутого функционального эффекта к размеру экономических затрат или капиталовложений. Данный подход позволяет оценить экономическую обоснованность КСУЭ предприятия в целом.

Предлагаемая система управления качеством электроснабжения на основе получаемых данных вырабатывает соответствующие управляющие воздействия, для реализации которых используются: исполнительная управляющая система, система контроля исполнения и система документооборота. Все это позволяет обеспечить надежность электропитания технологических объектов и безаварийность электрооборудования.

\section{СПИСОК ЛИТЕРАТУРЫ}

1. Электроснабжение промышленных предприятий: учебник / Б.И. Кудрин, О.А. Бушуева, А.В. Виноградов, Ю.В. Коновалов [и др.] - М.: Теплотехник, 2017. - 220 с.

2. Табачникова, Т.В. Оптимизация энергетических параметров в установившихся режимах электротехнических комплексах отходящих линий, подключенных к одному центру питания / Д.Н. Нурбосынов, Е.В. Рюмин, А.Д. Махт // Энергетика Татар- 